\title{
HYPONATREMIA IN HEPATIC CIRRHOSIS FOLLOWING PARACENTESIS ${ }^{1}$
}

\author{
By WILLIAM P. NELSON, III, JACK D. ROSENBAUM, AND MAURICE B. STRAUSS
}

(From the Medical Service, Cushing Veterans Administration Hospital, Framingham, Mass.)

(Submitted for publication January 15, 1951; accepted April 23, 1951)

The retention of water without a physiologically equivalent amount of sodium following abdominal paracentesis has been studied in two patients with advanced cirrhosis of the liver. In each there developed manifestations considered characteristic of sodium deficit, although there was no change in the total body sodium at the time these appeared. Such retention of water in excess of salt, regularly observed when large external losses of salt and water are replaced with water alone (1-3), has been noted in certain cases of heart failure and chronic renal disease (4-6) as well as in decompensated hepatic cirrhosis $(7,8)$. Whether the retention is primarily mediated through renal hemodynamic changes, altered tubular function, or increased antidiuretic activity is not clear. Observations concerning the development of this condition in two patients with cirrhosis are recorded below.

\section{METHODS}

During the periods of study both patients were offered diets calculated to contain 100 grams each of protein and fat, 300 grams of carbohydrate, approximately 100 $\mathrm{mEq}$. of potassium and no more than $15 \mathrm{mEq}$. of sodium. Dietary rejections were measured. Free access to water was allowed except when otherwise noted. The patients were weighed daily and the volume of urine collected during each 24 hour period was measured. The volume of fluid taken orally was estimated from conventional household measures. Venous blood samples were obtained daily in the post-absorptive state, without stasis in the first patient. Stasis was usually unavoidable in the second patient so that determinations of hemoglobin, hematocrit and serum protein were considered unreliable. The volume of packed red blood cells was measured in Wintrobe tubes (9); hemoglobin photometrically (10); serum total proteins by micro-Kjeldahl (11) and by gradient tube (12); chloride by Hald's modification of the Patterson micro-method (13); creatinine by Peters'

\footnotetext{
1 Reviewed in the Veterans Administration and published with the approval of the Chief Medical Director. The statements and conclusions published by the authors are the result of their own study and do not necessarily reflect the opinion or policy of the Veterans Administration.
}

modification of the Folin procedure (14); non-protein nitrogen by micro-Kjeldahl with Nesslerization (15); and sodium and potassium by means of the Barclay internal standard flame photometer. Except where otherwise noted, urine was collected over 24 hour periods and was analyzed for chloride by the Volhard-Harvey method (16), for total nitrogen by the micro-Kjeldahl procedure (11), and for creatinine, sodium, and potassium by the methods employed for serum. Change in total body water (liters) was taken to equal change in weight (kilograms).

\section{CASE REPORTS AND RESULTS}

\section{Case $I$.}

W. T. (CVAH No. 20063), a 58 year old white male, had been a chronic alcoholic for many years. One year before admission he developed ascites and jaundice at which time a low sodium diet was prescribed. $\mathrm{He}$ received frequent injections of mercurial diuretics but paracentesis was required for the relief of ascites, first monthly, later at two-week intervals. Following each paracentesis, disturbance of the sensorium of several days duration was regularly observed by the attending physician. Two days prior to the first hospitalization, paracentesis was performed and a mercurial diuretic was given. The patient also received 0.2 gram of sodium pentobarbital. Within a few hours he became hyperactive, confused, and vomited several times. At about this time he complained of cramps in his legs.

On admission (October 15, 1949) he appeared poorly nourished, acutely and chronically ill and was euphoric, confused, and slightly jaundiced. A few spider angiomata were present. The abdomen revealed signs of moderate ascites with a firm non-tender liver edge at the costal margin. The spleen was palpable $6 \mathrm{~cm}$. below the costal margin. Peripheral and sacral edema were absent. Tests of liver function were consistent with marked hepatocellular disease. There was a moderate normochromic anemia. The specific gravity of the urine was 1.029. No abnormalities were noted on routine urinalysis. Renal excretion of phenolsulfonphthalein was 64 per cent in two hours. The blood non-protein nitrogen was 42 mg. per $100 \mathrm{ml}$. The concentration of chloride in the serum was $92 \mathrm{mEq}$. per liter. Several grams of sodium chloride were given shortly after admission. The muscle cramps promptly disappeared and the mental confusion cleared rapidly. The serum chloride rose to $100 \mathrm{mEq}$. per liter and the NPN fell to $29 \mathrm{mg}$. per $100 \mathrm{ml}$. The patient was discharged 11 days after admission much improved, but with persistent moderate ascites. 
Abdominal paracentesis was again performed 16 days after discharge by the family physician and a week later, November 19th, the patient was readmitted in a state of confusion with clinical and laboratory findings as before. Without specific treatment he became oriented within 24 hours. Another paracentesis, performed in the hospital on December 3rd, was followed by confusion. He improved promptly when sodium chloride was given.

Detailed studies were carried out from December 14th to December 31st. (See Table I.) On December 15th, the serum sodium was 130 and chloride, $103.9 \mathrm{mEq}$. per liter. $\mathrm{CO}_{3}$ content was $18 \mathrm{mEq}$. per liter and showed no significant change throughout the study. The hematocrit was 30 per cent. Following the removal of 8.6 liters of ascitic fluid the weight was 58.17 kilograms. The patient became thirsty and ingested considerable water. Fortyfour hours later his weight had increased by 1.95 kilograms, the concentration of sodium in serum had fallen to 125 and that of chloride to $98.7 \mathrm{mEq}$. per liter, with the hematocrit rising to 34 per cent. Apathy, weakness, confusion, nausea and vomiting appeared. The blood pressure fell, with narrowing of the pulse pressure; marked tachycardia developed. The urine which had been scanty throughout was further suppressed prior to therapy. The serum non-protein nitrogen, consistently $40 \mathrm{mg}$. per 100 $\mathrm{ml}$. or less during the previous seven days, rose to 47 ; the serum creatinine, consistently below $1.09 \mathrm{mg}$. per $100 \mathrm{ml}$., rose to 1.22 on December 17th. On this date $188 \mathrm{mEq}$. of sodium chloride were given intravenously as a 3 per cent solution. The next day the patient remained confused and apathetic with continued hypotension and tachycardia. Although serum sodium was now $131.5 \mathrm{mEq}$. per liter, the hematocrit continued to rise to 37 per cent. Accordingly, an additional $402 \mathrm{mEq}$. of sodium chloride in 3 per cent solution, and 50 grams of concentrated human albumin were administered intravenously. On the following day clinical improvement was striking. The serum sodium was $138 \mathrm{mEq}$. per liter. The hematocrit had returned to 30 per cent.

The patient was then maintained on a regular diet without salt restriction. On December 26th, 10.3 liters of ascites were removed. The patient was requested to limit his fluid intake. Nevertheless, because of intense thirst, he drank large quantities of water. Sodium chloride was given in proportion of approximately $135 \mathrm{mEq}$. to each liter of water retained; $550 \mathrm{mEq}$. the day of paracentesis and 426 the following day. On this program the concentrations of sodium and chloride in serum remained normal and there was no evidence of hemoconcentration or nitrogen retention. The sensorium remained clear. No signs of circulatory impairment developed. Some nausea did occur but this may have been related to ingestion of salt tablets and to abdominal distention associated with the accelerated rate of reaccumulation of ascites.

The retention of water and sodium for the two periods described are represented in the table and Figure 1. During the first period water retention was large although the intake of sodium was initially very small. When symptoms developed 44 hours after the first para- centesis, hypertonic sodium chloride was required to restore the body water to relatively normal tonicity. During the second period, when very large amounts of sodium chloride were given, the patient reaccumulated ascites at a very rapid rate and again required paracentesis of 11.5 liters of fluid on December 30th. It is of interest that on the second day of this regime the urine contained $54 \mathrm{mEq}$. of sodium whereas the excretion was less than $1 \mathrm{mEq}$. on all other days.

On December 31st, the patient developed bronchopneumonia, from which time on his condition deteriorated rapidly. Enough sodium chloride was given each day to render the fluid intake approximately isotonic. The concentration of sodium in serum remained normal throughout the remainder of his course and no symptoms suggestive of salt depletion appeared. However, he gradually lapsed into coma with increasing jaundice, and despite apparently successful therapy of the pneumonitis with antibiotics, death in hepatic coma occurred on January 14, 1950.

Post-mortem examination confirmed the clinical diagnosis of advanced portal cirrhosis with esophageal varices.

Case II.

W. F. (CVAH No. 23530), a 58 year old white male, had consumed moderate quantities of alcohol for 25 years prior to hospitalization on May 3, 1950. He had noted anorexia and weight loss nine months before admission; two months later his abdomen began to swell. Three months prior to admission a paracentesis was performed; he was placed on a salt poor diet and received mercurial diuretics. Paracenteses were required at intervals of four to six weeks and were followed on each occasion by weakness and general malaise for two or three days unassociated with muscle cramps, disturbed sensorium or gastrointestinal symptoms.

On admission he appeared malnourished. The extremities were wasted and the abdomen was markedly distended. He was mentally alert. Numerous spider angiomata were present. Examination of the lungs and cardiovascular system revealed no abnormalities except for mild tachycardia and a blood pressure of 150/88. Numerous dilated superficial veins were present over the distended abdomen and frank signs of fluid were present. After the removal of ascitic fluid the edge of a firm non-tender liver could be felt $4 \mathrm{~cm}$. below the costal margin. The spleen was not felt. There was no subcutaneous edema.

A mild hypochromic anemia was present. Urinalysis was unremarkable except for a specific gravity of only 1020 despite marked oliguria. Tests of liver function indicated marked hepatocellular, damage, although bilirubin levels were normal. $\mathrm{CO}_{2}$ content was 20.4 to $23.4 \mathrm{mEq}$. per liter during the period of study. Other data, recorded in the table, indicated moderate impairment of renal function. X-ray examinations failed to demonstrate esophageal varices but revealed a benign appearing ulcer crater on the lesser curvature of the stomach.

Shortly after admission the diet previously described, containing approximately $15 \mathrm{mEq}$. of sodium, was given. 


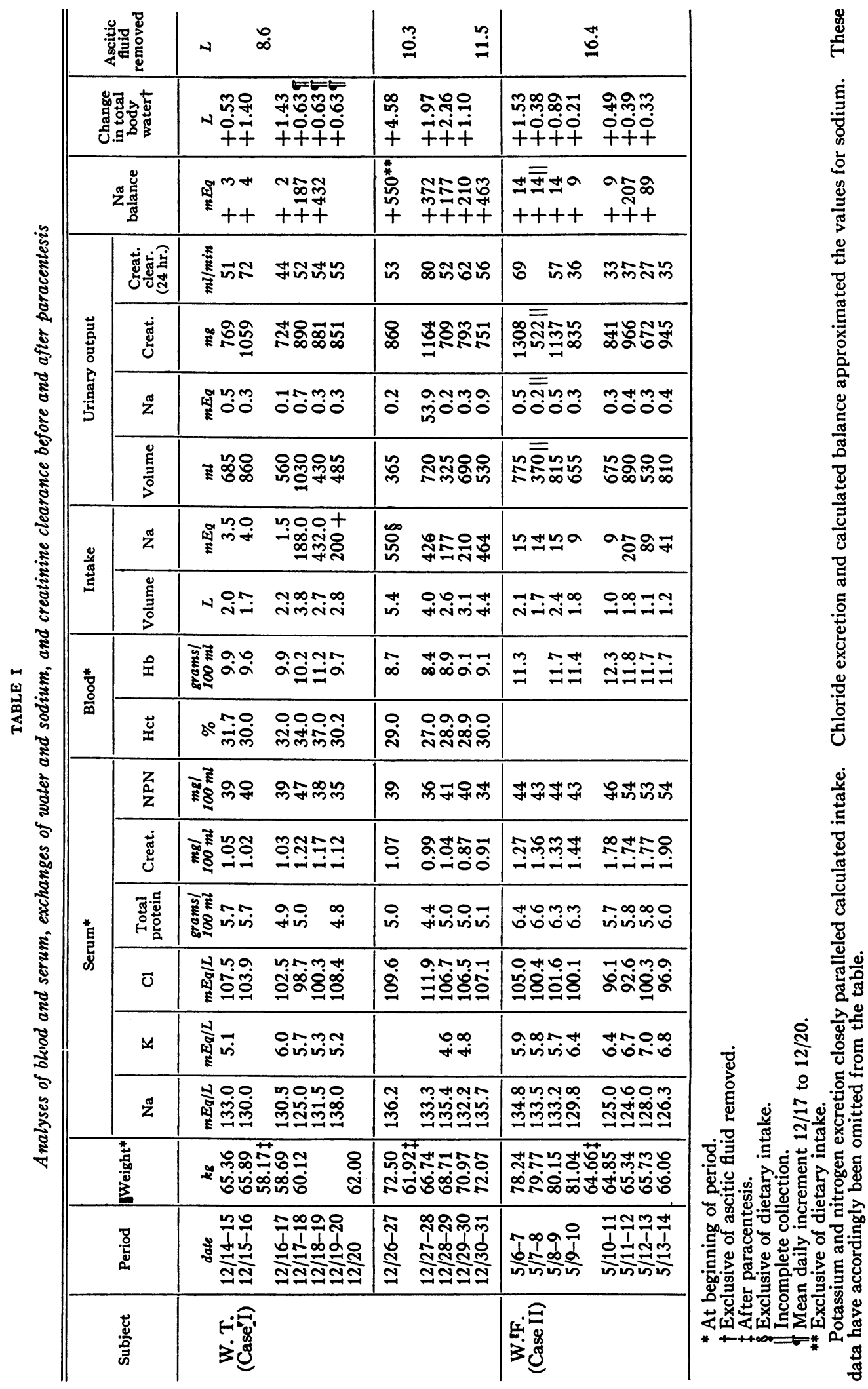




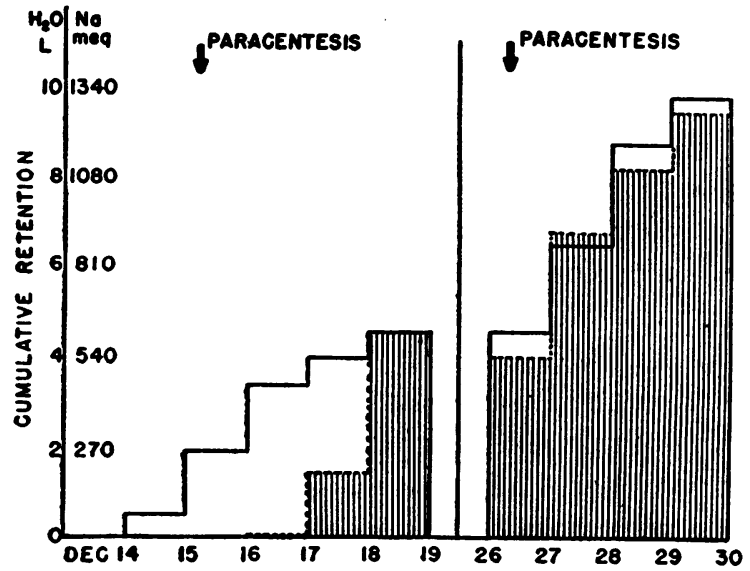

Fig. 1. Case i. Cumulative Retention of Total Body Water and Sodium

Ordinate scale constructed to represent $135 \mathrm{mEq}$. of sodium equivalent to 1.0 liter of water. Dotted line above hatched area represents retained sodium. Solid line represents water retained. Open area represents water retained in excess of sodium.

From May 6th to May 9th, before paracentesis, his weight increased almost 3 kilograms (Table I). During this period the concentration of sodium in serum fell from 134.8 to $129.8 \mathrm{mEq}$. per liter and that of chloride from 105.0 to 100.1 while serum potassium rose from 5.9 to $6.4 \mathrm{mEq}$. per liter. On May 9th, 16.4 liters of ascitic fluid were removed by paracentesis. The next morning, the concentrations of sodium and chloride in serum were 125.0 and $96.1 \mathrm{mEq}$. per liter respectively. On the morning of May 11th, the serum chloride had fallen further to $92.6 \mathrm{mEq}$. per liter, while the concentration of sodium appeared to have remained essentially unchanged and carbon dioxide content increased by $2 \mathrm{mEq}$. per liter. Serum potassium had increased to $6.7 \mathrm{mEq}$. per liter and the non-protein nitrogen to $56 \mathrm{mg}$. per $100 \mathrm{ml}$. However, the patient remained quite comfortable and ate well. During the afternoon increasing weakness and fatigue were noted together with some nausea. The patient refused supper and at midnight complained of severe nausea and persistent hiccoughs. He was distressed and apprehensive but the sensorium was clear and no muscle cramps developed. The pulse rate rose from 80 to 106 with a fall in blood pressure from 120/80 to $95 / 80$. This deterioration of the clinical condition was unassociated with any further change in the concentration of sodium or chloride in serum, but by midnight, 60 hours after the paracentesis, the potassium rose even higher to $7.4 \mathrm{mEq}$. per liter. He was given $200 \mathrm{mEq}$. of sodium chloride as a 3 per cent solution intravenously at this time. During the next eight hours nausea gradually disappeared and he became much more comfortable. The concentration of chloride in serum rose to $100.3 \mathrm{mEq}$. per liter and that of sodium to 128 , while potassium fell to 7.0 and carbon dioxide content by $2.8 \mathrm{mEq}$. per liter. Hiccoughs continued for 12 hours longer. He then received an additional $85 \mathrm{mEq}$. of sodium chloride by mouth. Within 36 hours his strength and sense of well being had been restored and the pulse and blood pressure had returned to their original values. However, without administration of salt, the concentration of sodium and chloride in serum fell about $3 \mathrm{mEq}$ per liter. The non-protein nitrogen did not fall, but serum potassium decreased further to $6.6 \mathrm{mEq}$. per liter on May 15th.

In the three day period prior to paracentesis, there had been retention of approximately 2.8 liters of water in excess of sodium (Table I, Figure 2) with an associated decline of $5 \mathrm{mEq}$. per liter in the concentration of sodium and chloride in serum. The calculated additional retention of water without salt during the 60 hours after paracentesis approximated only $800 \mathrm{ml}$. but the serum sodium declined by 5 and the chloride by $7 \mathrm{mEq}$. per liter during this period. During the 32 hour period after the administration of hypertonic saline, the increase in total body water as indicated by weight gain of 0.4 kilogram was small, but the increase in extracellular volume calculated from change in concentration of chloride in serum and chloride balance (17) was 2 liters. On May 13th, the patient began to leak fluid from the paracentesis puncture site and balance studies were discontinued.

Subsequently, a diet containing liberal amounts of sodium chloride was given and there were no further manifestations of salt deficiency. During the next two months there was slight clinical improvement and the abnormalities in tests of hepatic function became less marked. Additional paracenteses were required at monthly intervals. Some nitrogen retention persisted and endogenous creatinine clearance on June 22nd was only $29 \mathrm{ml}$. per minute. The gastric ulcer failed to heal and a second crater subsequently appeared. The patient died on August 4, 1950, following repeated episodes of gastrointestinal bleeding. Findings at post mortem examination included portal cirrhosis of the liver with esophageal

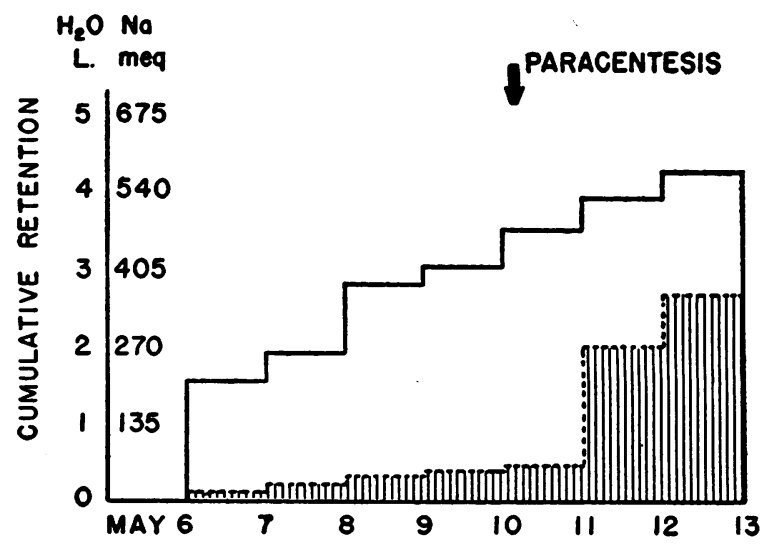

Fig. 2. Case it. Cumulative Retention of Total Body Water and Sodium (represented as in Figure 1)

Paracentesis performed late afternoon of May 9th. 
varices; two benign gastric ulcers; and benign arteriolar nephrosclerosis of moderate severity.

\section{DISCUSSION}

Manifestations observed in the first patient included hyponatremia, apathy, weakness, confusion, anorexia, nausea, vomiting, muscle cramps, hypotension, narrow pulse pressure, tachycardia, hemo-concentration and elevation of the serum non-protein nitrogen. Following the administration of hypertonic saline these disappeared. Furthermore, the syndrome failed to develop when isotonic saline was given after the second paracentesis. The second patient's symptoms were less severe but equally characteristic. The sensorium remained clear although depression and apprehension were noted. He became nauseated and had hiccoughs but did not vomit. Circulatory impairment, as reflected by hypotension and tachycardia, was unequivocal. Hyponatremia and hypochloremia were present. Nitrogen retention, present on admission, became more marked after paracentesis. The administration of sodium chloride produced marked improvement although the concentration of non-protein nitrogen and creatinine in the serum remained elevated.

In both patients, the urine volume remained small throughout, averaging about $600 \mathrm{ml}$. daily in Case I and approximately $750 \mathrm{ml}$. daily in Case II. Both patients retained water even though sodium was not given, so that hyponatremia necessarily developed. In Case I, although physical signs indicated rapid reaccumulation of ascitic fluid during the first 24 hours after the paracentesis of December 15th, the calculated increase in total extracellular fluid volume during this first day was negligible ( 0.13 liters) and the hematocrit rose but slightly, suggesting that losses of plasma water and electrolyte into the peritoneal cavity were being replaced at the expense of transfers from the interstitial extracellular compartment.

In the second patient, water was being retained in excess of sodium prior to paracentesis. Nevertheless, symptoms did not develop until about 60 hours after paracentesis. Although weight did not increase at an accelerated rate after paracentesis, the concentrations of sodium and chloride in serum underwent a further abrupt fall. The mechanism of this change is not clear, but re- quires either a shift of sodium chloride into cells or, due to alteration of intracellular osmolarity, a movement of water out of cells.

Both patients developed symptoms concomitant with the decline in concentration of sodium in serum during the days following paracentesis. This decline occurred despite the presence of an abnormally large total volume of extracellular fluid with an excessive total body content of sodium. However, with segregation in the peritoneal cavity of a considerable portion of the total volume of extracellular fluid (ascitic fluid plus interstitial fluid plus plasma), it appears likely that the extraperitoneal extracellular fluid volume (interstitial fluid plus plasma) was actually reduced. Certainly the plasma volume, as judged by the rising hematocrit in Case I, was diminished. Mankin and Lowell (18) observed that patients with cirrhosis characteristically reaccumulate ascites most rapidly during the first three days after paracentesis. In one of their patients ascitic fluid volume expanded by 2 liters during the first 24 hours after tapping, while body weight increased by only 1 kilogram. At least a liter of extraperitoneal extracellular fluid must therefore have been transferred into the peritoneal cavity. That transport of extraperitoneal extracellular fluid into the peritoneum frequently occurs after paracentesis is further supported by the clinical observation that when subcutaneous edema is present, it often decreases during this period, although body weight may not fall (19).

Several observations suggest that contraction of the extraperitoneal extracellular fluid volume (which, apart from any edema, might be called the "effective" extracellular volume) is an important feature of the syndrome. The second patient (W. F.) underwent two subsequent paracenteses after he had developed moderate dependent edema. No untoward manifestations appeared despite the fact that no extra salt was given and reaccumulation of ascites was initially rapid. The edema decreased without weight loss during the days following each paracentesis. This has been observed in other patients with ascites whose edema disappeared after paracentesis while their weight remained stationary and ascites increased. Presumably the edema fluid mobilized served to maintain the effective volume of extracellular fluid since symptoms did not appear de- 
spite moderate hyponatremia which was present before and after paracentesis and which showed no significant change after paracentesis. Others who have observed the occurrence of weakness and circulatory impairment after paracentesis state that they have encountered these symptoms only in patients with little or no peripheral edema who reaccumulate ascites rapidly $(20,21)$.

That hemoconcentration of some degree frequently follows paracentesis in patients with hepatic cirrhosis is evidenced by the observations of Gabuzda and his associates (19). A patient has been observed by us who developed severe hemoconcentration and became comatose on two occasions within 48 hours after paracentesis, and on each occasion was relieved by the intravenous infusion of salt poor human albumin. In the first case reported here, $W$. T., it seems probable that the administration of albumin might well have not only corrected the hemoconcentration but also the extreme thirst which presumably resulted from the contracted blood volume (22) and which directly led to the large water ingestion and consequent hyponatremia. Certainly the frequent occurrence of moderate hyponatremia in patients with decompensated cirrhosis without symptoms of salt deficiency $(7,8)$ suggests that hypotonicity alone, although hardly beneficial, does not produce the clinical syndrome described. It thus seems probable that a decrease in effective extracellular volume is a necessary event in its pathogenesis, and that the administration of hypertonic saline serves to correct both the hypotonicity and the diminished plasma volume.

Although the various manifestations encountered in the patients described above were similar to those encountered with diverse causes of salt deficit, the loss of water and electrolytes was into the peritoneal cavity rather than externally. The retention of ingested water without salt may have represented an attempt to restore the decreased effective extracellular volume or the diminished plasma volume at the expense of electrolyte concentration. If isotonic saline or edema fluid was available in sufficient quantity to provide for the obligatory reaccumulation of ascites, the syndrome did not occur. Once it had developed, however, hypertonic saline was necessary to restore electrolyte concentration and effective extracellular volume.
Rigid restriction of the intake of sodium has been widely practiced with a large measure of success in the management of patients with hepatic cirrhosis and ascites $(7,23-26)$. The infrequency of the development of the low-salt syndrome in patients so treated has been emphasized $(24,27)$. Although chronic hyponatremia in hepatic cirrhosis is common, it appears to be related to the severity of decompensation $(7,8)$ and does not necessarily depend upon rigid salt restriction. However, a tendency for serum sodium to fall in patients with hepatic cirrhosis treated by means of a diet poor in sodium has been reported by Farnsworth and Krakusin (28). Similar observations have been made by Eisenmenger and associates $(8,24)$, who described symptoms suggesting sodium deficit in two of 13 cases treated. However, in one patient the symptoms were very mild and in the second their relationship to sodium restriction was unclear. Symptomatic hypochloremia in hepatic cirrhosis was probably first described by Porges in 1932 (29). Mach and associates (30) recognized hypochloremia following repeated paracenteses, but observed no associated symptoms. Gabuzda and colleagues (19) have noted moderate hyponatremia to be a frequent transitory event after paracentesis, an observation confirmed by others (8).

It seems probable that if the syndrome described above occurred frequently in severe form, it would no doubt have been recognized more often in the past. The observations presented do not detract from the therapeutic value of salt restriction in cirrhosis, nor do they indicate that the large amounts of salt administered in this study will often be required. The available information suggests that the abnormality rarely becomes severe enough to produce symptoms. Moreover, these often may be mild and disappear without therapy specifically directed at their correction.

\section{SUM MARY}

1. The development of symptomatic hyponatremia following abdominal paracentesis in two patients with cirrhosis of the liver has been described.

2. The manifestations were corrected by administration of sodium chloride in hypertonic solution.

3. Development of the syndrome was apparently prevented in one patient when his fluid intake after 
paracentesis was limited to isotonic saline. In the other patient, when subcutaneous edema was present on a later occasion, its mobilization after paracentesis appeared to prevent the symptoms.

4. It is suggested that although total extracellular fluid volume was large, the extraperitoneal (effective) extracellular fluid volume was actually decreased in both patients when the syndrome developed.

\section{ACKNOWLEDGMENTS}

The technical assistance of Miss Elsie C. Rossmeisl, Mrs. Eleanor G. Harkins, and Miss Helen G. Lichwell is gratefully acknowledged.

\section{REFERENCES}

1. Kerpel-Fronius, E., Uber die Beziehungen zwischen Salz- und Wasserhaushalt bei experimentellen Wasserverlusten. Ztschr. f. Kinderh., 1935, 57, 489.

2. McCance, R. A., Medical problems in mineral metabolism. III. Experimental human salt deficiency. Lancet, 1936, 1, 823.

3. Nadal, J. W., Pedersen, S., and Maddock, W. G., A comparison between dehydration from salt loss and from water deprivation. J. Clin. Invest., 1941, 20, 691.

4. Peters, J. P., The role of sodium in the production of edema. New England J. Med., 1948, 239, 353.

5. Schroeder, H. A., Renal failure associated with low extracellular sodium chloride. J.A.M.A., 1949, 141, 117.

6. Welt, L. G., Panel discussion on edema. Presented at the annual meeting of the American College of Physicians, Boston, April 18, 1950.

7. Combined Staff Clinic (College of Physicians and Surgeons, Columbia University), Mechanisms of ascites formation. Am. J. Med., 1950, 9, 102.

8. Eisenmenger, W. J., Blondheim, S. H., Bongiovanni, A. M., and Kunkel, H. G., Electrolyte studies on patients with cirrhosis of the liver. J. Clin. Invest., 1950, 29, 1491.

9. Wintrobe, M. M., Clinical Hematology. Lea \& Febiger, Philadelphia, 1947, Ed. 2, p. 242.

10. Sanford, A. H., Sheard, C., and Osterberg, A. E., The photelometer and its use in the clinical laboratory. Am. J. Clin. Path., 1933, 3, 405.

11. Hiller, A., Plazin, J., and Van Slyke, D. D. A study of conditions for Kjeldahl determination of nitrogen in proteins. J. Biol. Chem., 1948, 176, 1401.

12. Lowry, O. H., and Hunter, T. H., The determination of serum protein concentration with a gradient tube. J. Biol. Chem., 1945, 159, 465.
13. Peters, J. P., and Van Slyke, D. D., Quantitative Clinical Chemistry. Volume II. Methods. Williams \& Wilkins, Baltimore, 1932, pp. 838-839.

14. Peters, J. H., The determination of creatinine and creatine in blood and urine with the photoelectric colorimeter. J. Biol. Chem., 1942, 146, 179.

15. Hawk, P. B., Oser, B. L., and Summerson, W. H., Practical Physiological Chemistry. Blakiston, Philadelphia, 1947, Ed. 12, pp. 495-497.

16. Peters, J. P., and Van Slyke, D. D., op. cit., pp. 833835.

17. Elkinton, J. R., and Taffel, M., Prolonged water deprivation in the dog. J. Clin. Invest., 1942, 21, 787.

18. Mankin, H., and Lowell, A., Osmotic factors influencing the formation of ascites in patients with cirrhosis of the liver. J. Clin. Invest., 1948, 27, 145.

19. Gabuzda, G. J., Jr., Treager, H. S., and Davidson, C. S., Hepatic cirrhosis. Factors contributing to the failure to excrete urinary sodium during the accumulation of ascites and edema. J. Clin. Invest., 1950, $29,814$.

20. Welt, L. G., Personal communication.

21. Kunkel, P., Personal communication.

22. Beecher, H. K., Early care of the seriously wounded man. J.A.M.A., 1951, 145, 193.

23. Layne, J. A., and Schemm, F. R., The use of a high fluid intake and a low-sodium acid-ash diet in the management of portal cirrhosis with ascites. Gastroenterology, 1947, 9, 705.

24. Eisenmenger, W. J., Ahrens, E. H., Jr., Blondheim, S. H., and Kunkel, H. G., The effect of rigid sodium restriction in patients with cirrhosis of the liver and ascites. J. Lab. \& Clin. Med., 1949, 34, 1029.

25. Chalmers, T. C., and Davidson, C. S., A survey of recent therapeutic measures in cirrhosis of the liver. New England J. Med., 1949, 240, 449.

26. Faloon, W. W., Eckhardt, R. D., Cooper, A. M., and Davidson, C. S., The effect of human serum albumin, mercurial diuretics, and a low sodium diet on sodium excretion in patients with cirrhosis of the liver. J. Clin. Invest., 1949, 28, 595.

27. Davidson, C. S., and Gabuzda, G. J., Jr., Nutrition and disease of the liver. New England J. Med., 1950, 243, 779.

28. Farnsworth, E. B., and Krakusin, J. S., Electrolyte partition in patients with edema of various origins. Qualitative and quantitative definition of cations and anions in hepatic cirrhosis. J. Lab. \& Clin. Med., 1948, 33, 1545.

29. Porges, O., Uber Coma hypochloraemicum. Klin. Wchnschr., 1932, 11, 186.

30. Mach, R. S., Mach, E., and Sciclounoff, F., Déchloruration et urémie. La chloropénie des ascitiques ponctionnés. Schweiz. med. Wchnschr., 1934, 64, 54. 